\title{
Decisions: Problems or Opportunities?
}

\author{
How you can prevent unpleasant decision situations
}

\author{
Many individuals and organizations face and address decision situations as \\ problems, which are to be solved. However, decisions are the only way to \\ influence actively what is important. This paper differentiates decision \\ problems and decision opportunities and illustrates how proactive, value- \\ focused decision making can create attractive decision opportunities and \\ help reduce the chance of some unwanted decision problems.
}

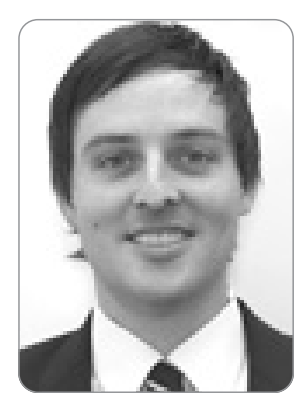

FH-Prof. PD Dr. habil. Johannes Ulrich Siebert

is professor at the Management Center Innsbruck and Private Lecturer at the University of Bayreuth.

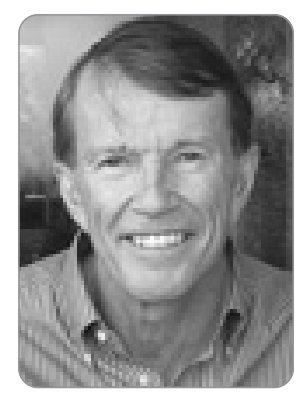

Prof. Dr. Ralph L. Keeney

is Research Professor Emeritus at Duke University (US).

Keywords: Decision theory, proactive decision-making, value-focused thinking, decision problems, decision opportunities

\section{Decision situation are perceived and faced as problems}

Decisions are the only way to influence what is important for you or your organization (Keeney, 2020). Nevertheless, decision situations are often perceived and faced as problems. In academia as well as in practice, this is even manifested in the language - decisions are referred to decision "problems". There are several reasons for this. For example, making a decision means taking over responsibility, reducing one's decision freedom in the future (someone who buys a house today invests his or her financial resources for this purpose and cannot use them to buy a car tomorrow), and using cognitive effort to think through the decision situation. As a consequence, many individuals as well as organizations tend to procrastinate in making their decisions.

Many individual and organizational decision-makers are content with the status quo even if they are not satisfied with it or they perceive that the status quo degrades over time. They behave reactively instead of proactively. For example, married couples seek marriage guidance on average seven years too late. Then, the level of suffering is already at a high level and there is a "severe problem which is very difficult to solve".

The following example illustrates a situation, which many families may have to face if they only make reactive decisions over a long period.

Mary and Anton, both 55 years old, are living in a small town in Tyrol. They are supporting three children, one of which is going to school and two are studying at a university. Twenty-five years ago, the couple decided that Mary, a trained office clerk, should quit her job to take care of the children and the home while Anton, a trained industrial mechanic, would be the sole wage earner. Anton is working for a medium sized automotive supplier with 800 employees of which 200 are industrial mechanics.

A large international enterprise buys the company in Tyrol and announces on short notice to relocate the production to Asia. Subsequently, Anton looses his job and therewith his family's livelihood. Anton faces severe difficulties getting a new job, in particular because not only he but also 199 other industrial mechanics with similar qualifications and many of them younger and therefore cheaper - are searching for new jobs. Without Anton's salary, the parents 
cannot support the education of their children. The family cannot pay the monthly instalment for the large house and has to move into a smaller house in a cheaper neighborhood. Anton feels a failure because he cannot provide for his family anymore and spends most of his time sitting on the sofa in a very bad mood. This strains his relationship to his wife Mary substantially. In such situations, entire families are threatened to break apart.

Needless to say that the family is facing a serious problem. In such a situation, many individuals complain about their fate and conclude that it was just bad luck since they could not have done anything about it the company being sold, the production relocated, and the employees laid off. It is correct that employees usually do not have substantial influence on whether their company is sold. However, on an individual basis, there were likely several opportunities to influence one's life proactively (for example, by reducing the probability of getting laid off, and in case it occurs, by increasing at the chances to find an appropriate job).

This paper differentiates decision problems and decision opportunities and illustrates how proactive, value-focused decision-making cannot only reduce the probability of serious decision problems but also can help to identify very attractive decision opportunities.

\section{Value-focused Thinking vs. Alternative-focused Thinking}

The typical and most commonly used decision process in practice consists of four steps. In the first step, the decision problem is identified. This is often triggered by dissatisfaction with the current situation related to a wish for improvement. In the second step, the decision maker searches for potential solutions for his or her decision problem and identifies quickly and without much effort a couple of "obvious" alternatives. Often, one or more already identified alternative(s) serves as a starting point. For example, if a family really enjoyed their vacation on the island Corfu in Greece last year, then similar alternatives are developed when planning the next holiday without substantial changes, for example, Corfu, Rhodes, Samos, or Crete. However, the North Sea, Spain, and Turkey will not be identified as alternatives. It may also happen that an unforeseen alternative opens up and the decision between this and the status quo has to be made. In both cases, the decision maker selects in the third step a couple of criteria representing his or her perspective on the relevant consequences of the alternatives. In the fourth step, the decision maker examines the gathered information and makes his or her decision on that basis.

Keeney (1992) refers to such an orientation on obvious alternatives in the decision making process as alternative-focused thinking. For many individuals, alternative-focused thinking seems to be the "natural" way of making decisions. Already the first decisions in early childhood, for example the decision between ice cream or chocolate, as well as experiences with later decisions make individuals perceive decisions as the choice among given alternatives. Despite the fact that alternative-focused thinking is widely applied, it has several severe deficiencies. The choice among obvious alternatives may, at first glance, "solve" the decision problem. On closer inspection, it becomes however clear that it cannot be the primary goal just to solve decision problems reactively. Instead, decisions should be used to shape the environment actively and to achieve what you want. It is a coincidence if the potentially best alternative was amongst the obvious ones (Siebert and Keeney, 2015). The reason for that is that the identification of alternatives happens in a "vacuum" and is not clearly related to the values and objectives of the decision maker (Keeney, 1992, S. 44 pp).

Exactly this relationship is the core idea of value-focused thinking. Values define what is important for a decision maker and are fundamental for all that this decision maker undertakes. Therefore, these values should guide the decision making process. The values of a decision maker are the reason why he or she should invest time and cognitive effort in decision making (Keeney, 1996, S. 537). In comparison to alternative-focused thinking, value-focused thinking implies a change of paradigm becoming apparent by three aspects. First, a significant effort is spent to become aware of, clarifying, and formulating the values. Second, logical concepts state the values as objectives and organize them. Third, the objectives are used explicitly to identify more and better alternatives and decision opportunities (Keeney, 1996, pp 537).

In the last years, several empirical studies suggesting the need for and the effectiveness of proactive, value-focused decision-making. Bond et al. (2008) showed that decision makers are only aware of the half of their objectives relevant to their decision situation. However, how could you make good decisions if you are not aware of your objectives? Siebert and Keeney (2015) analyzed the ability to identify alternatives in decision situations. In their first study, the decision situation was about creating alternatives that could contribute to achieving one's objectives during an internship, for example, to get a full-time offer, to develop certain skills, or to network. The participants were business students who had already carried out an internship or who were planning an internship currently. Therefore, it can be assumed that the participants had already spent substantial effort thinking about this decision situation. Even though, without help the participants were able to identify only about one third of the alternatives relevant to them. More than half of the participants even overlooked their potentially best alternative. In four further studies, the au- 
thors showed that using objectives as stimulus leads to more and better alternatives. In the task of finding a title for an academic paper, more experienced participants usually create better titles. However, undergraduate students stimulated with objectives were able to create alternatives as good as more experienced graduate and PhD students not prompted with objectives (Siebert, 2016).

Proactive, value-focused decision-making of individuals in decision situations can be described with six dimensions. The two dimensions "showing initiative" and "striving for improvement" relate to aspects of proactive personality. The dimensions "systematical identification of objectives", "systematic identification of alternatives", "systematic gathering of relevant information", and "using a decision radar" measure the proactive cognitive skills of individuals in decision situations (Siebert and Kunz, 2016). Proactive decision-making explains about $50 \%$ of the variation of decision satisfaction and also about $35 \%$ of the variation of life satisfaction (Siebert et al., 2020). If you internalize the differences between decision problems and decision opportunities discussed in this paper and search for decision opportunities more actively, then you act more proactive in decision situations. As a consequence, you significantly enhance your chance to be more satisfied with your life in the long run!

\section{Decision problems vs. decision opportunities}

It is important to differentiate between decision problems and decision opportunities. However, many decision makers are not aware of the difference.

"Decision problems are decisions that you must face as a result of others' decisions and/or circumstances beyond your control" (Keeney, 2020). These decision problems are to be "solved". Decision makers often consider only the obvious alternatives, those used in the past in similar situations, or alternatives suggested by others.

If someone loses his or her job due to a reorganization of the company, this is a problem and it requires one or more decisions to find a new job. What if someone offered you unexpectedly a very attractive job in an interesting company, which would mean a career jump for you? In this decision situation, you have to make one or more decisions, too. Nevertheless, does this pose a "problem"? Although it is positive situation, it is still a decision problem because you have to react to such a decision of another person or organization (Keeney, 2020).

Decision makers purposely create and control decision opportunities. In order to better understand decision opportunities, the following question is very helpful: who should make your decisions? The answer is trivial: you should make your decisions. Contrarily, the answer to the next question seems to be for many individuals not so trivial: who should decide which decision situations you should deal with? Ideally, it is again you; maybe not always, but as often as possible.

Consider an example that is relevant for many people. Paul has to commute more than one hour in a train every day. He got used to using this time by playing with his smart phone or surfing the Internet. Paul does not have a problem. Nevertheless, he could create a decision opportunity proactively by asking how he could use the time more effectively. He could do something he is interested in, relaxes him, saves him time, he really enjoys, etc.

\section{Reactive vs. proactive decision-making}

The difference between reactive, alternative-focused decision-making and proactive, value-focused decision-making can be illustrated with Claudia's health. Claudia is a reactive decision maker. Initially, everything is fine with her health. Then, when playing soccer, she twists her ankle resulting in a torn ligament. She has to face a decision problem: which doctor should she visit? Subsequently her doctor has a decision problem: which tests should be used for diagnosis? Afterwards, Claudia and the doctor have another decision problem: which treatment should be used? If everything goes well, Claudia can play soccer again a couple of weeks later. However, in a couple of months, she twists her ankle again and the procedure repeats, as in every season. She always seems to have bad luck, or does she? Not necessarily. She could have dealt with her foot injuries proactively when she had no injury. Her objectives are obvious; she wants to prevent her foot injuries and continue playing soccer. What could she do so that she does not twist her foot so often (or ideally not at all)? There are numerous options! For example, she could use special shoes or orthopedic bandages. Furthermore, she could do special exercises to strengthen her muscles and ligaments, or she could avoid playing on artificial turf if she always twists her ankle on this surface.

There are many studies linking a high body mass index, insufficient exercise, alcohol consumption, or smoking in the long run with substantial health problems. Reactive decision makers tend to wait until one of these potential problems becomes acute. Then they are confronted with serious decision problems to be solved, for example, which heart surgery is the best one. Instead, proactive decision makers recognize potential problems in the future and take measures for prevention proactively. For example, they exercise a little more, drink less alcohol, have a better diet, etc. Nevertheless, it is important to emphasize that there is no sure way to avoid problems; people can really have "bad luck". However, proactive decision making can reduce the likelihood of undesired events. 


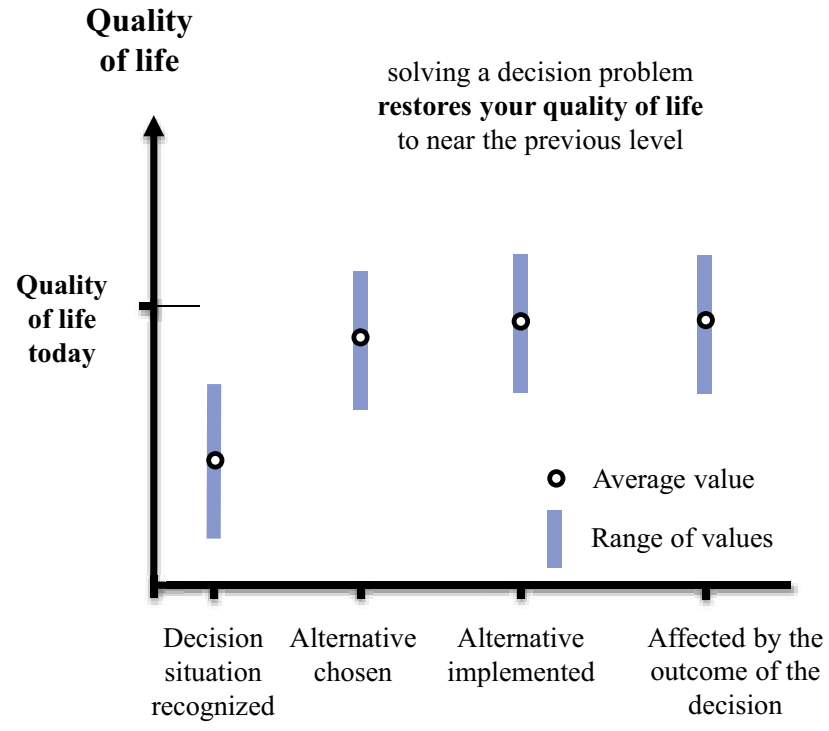

Milestones in decision situations

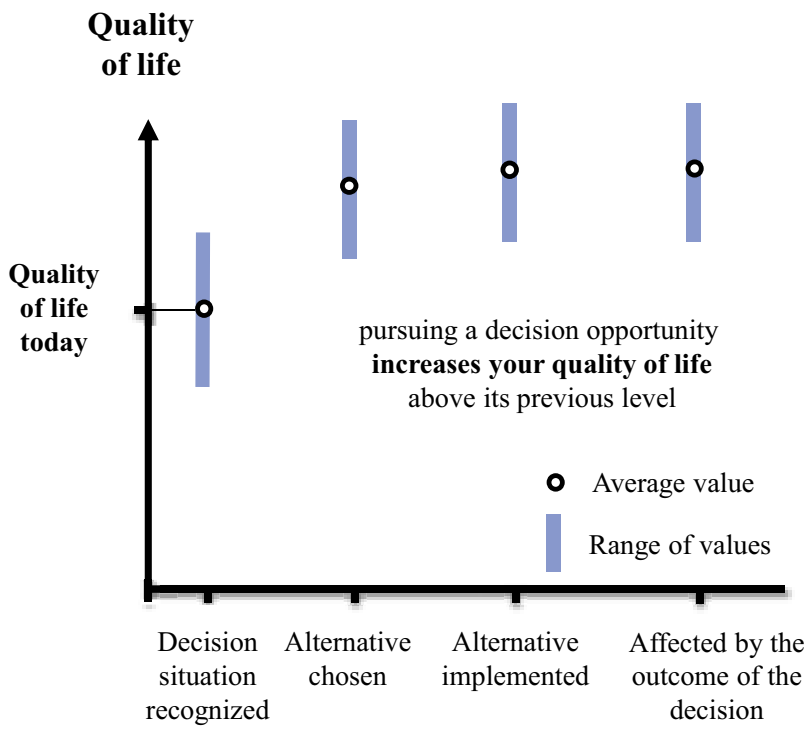

Milestones in decision situations

Figure 1: The quality of life at four milestones of decision situations for decision problems and decision opportunities based on Siebert and Hannes (submitted)

\section{How decision situations influence the quality of life}

An essential difference between decision problems and decision opportunities is how they affect what is important to the decision maker. In the case of individuals, we will focus in the following on the most general construct the quality of life; examples for more specific constructs include satisfaction, fitness, health, income, etc.

In case of decision problems, the quality of life will have deteriorated due to an event beyond the decision maker's control, for example, the car is broken, the leave of absence is denied, a tornado destroys the roof, one gets the flu, etc. The quality of life is thus reduced. So the decision maker tries to solve the decision problem: the car will be repaired, the roof tiled, a doctor's appointment arranged, etc. When the problem is solved, the quality of life is more or less restored in most cases which is illustrated on the left side of Figure 1. However, on average a slightly lower level of the quality of life is assumed (Keeney 2020). For example, if Claudia ruptures her ligaments regularly, then it is likely that the functionality of her foot will be deteriorated in the long run. Figure 1 indicates the average value and the range of values for the consequences of potential alternatives solving decision problems.

The quality of life does not worsen if a decision opportunity is not pursued. However, for example, if Claudia decides to strengthen her ligaments and muscles with physiotherapy and regular gymnastics, she may reach a higher level of functionality of her feet over time and thus reduce the probability of rupturing her ligaments in the future, which would lead to a higher quality of life. The quality of life over time for decision opportunities is illustrated on the right side of Figure 1. It indicates the general consequen- ces of pursuing decision opportunities over time. Pursuing decision opportunities improves the quality of life on average (Keeney, 2020).

\section{How to prevent problems proactively}

In context of health, many people try to avoid or minimize the probability of undesired conditions through active prevention. People take preventive actions or arrangements also in other areas of life, even if the probability of the events is extremely low, e.g. flooding, traffic accidents, or a nuclear meltdown in the nearby power plant. Such preventive actions (alternatives) are obvious and are in most of the cases presented to the decision makers by someone else, for example, by insurance agents or sales representatives for survival kits and nuclear shelters for your garden. The decision makers can choose the most feasible alternative with only little effort. If there are no such alternatives presented, many people remain in their status quo until an event beyond their control significantly deteriorates the quality of their life. The consequences of such passive behavior can be dramatic.

In the following, the example of the reactive sole wage earner Anton from Tyrol is considered and it is shown how the problem might have been alleviated or even prevented. Anton and Mary should have started acting systematically and proactively in their decision situations 25 years ago. In particular, they should have thought about which alternatives might help to reach their objectives.

As a starting point, it is necessary to identify Anton and Mary's objectives. For this purpose, it is very helpful for them to think about desirable and undesirable consequences. For sure, losing their livelihood is a severe and undesi- 
rable consequence. Hence, "maximizing financial security" can be identified as one fundamental objective. Beside this objective, there are certainly other relevant objectives. In order to keep this paper concise, only this one objective is used to illustrate Anton and Maria's proactive decision-making process. However, in practice it is highly recommended to consider also other relevant objectives. Thus, here the question is: what opportunities did the family have to achieve their objective "maximizing financial security" in case of Anton's dismissal?

- Mary could have taken a part-time job which she could increase if necessary

- Mary could have - at least in the last 10 years - improved her qualifications and worked for an organization from home

- The children could have financed their studies with scholarships or part-time jobs

- The family could have bought a smaller house for which they would not have had to take a loan, they have now difficulties paying back

In the following, we look at the opportunities of the sole wage earner Anton that have not been considered yet. In particular, we focus on his professional activities: how can employees achieve their fundamental objective "maximizing financial security"? For example, by pursuing the objectives "reducing the probability of being dismissed" and "increasing the probability of getting an appropriate job quickly in case of dismissal". Which decision opportunities might Anton have pursued to achieve these objectives?

- Anton could have been continuously improving his qualifications. Thereby, he could have thought of which skills would gain relevance in his professional field in the future and focused on them, for example IT, robotics, team leadership, English, etc.

- Anton could have networked better, for example by participating at certain events for employees and employers in his field

- Anton could have informed himself on a regular basis about potential employers

This list is certainly not complete. Anton would not have had to pursue all opportunities at the same time. Investing one to two hours per week in pursuing some of these opportunities would likely have been sufficient. Such an investment of time seems to be more than reasonable in comparison to potential undesirable consequences. Many sole wage earners like Anton would now wish to have spent such an effort in the last years. Furthermore, the improved skills could also enhance the chance of getting promoted so that the "investment" would very likely be amortized soon.

\section{Conclusion: How you get what you want}

Many individuals and organizations perceive and face decision situations as problems to be solved. This basic attitude is reactive and focuses in most cases on restoring the status to that before the problem occurred. In contrast, Keeney (2020) suggests addressing decision situations proactively by identifying decision opportunities systematically. The example of Anton from Tyrol illustrates how proactive, value-focused decision making can reduce the probability of future decision situations with severe negative consequences.

Proactive, value-focused thinking can also increase the probability of getting what you dream about. For this, you have to first identify your values and objectives and then use them to systematically create decision opportunities. For example, many students consider their thesis as a tiresome obligation, i.e. as "a problem to be solved". In this case, you should "reframe your decision situation" by changing the decision problem to a decision opportunity. Identify your objectives. If you wish to work for a certain company, think about how you could use your thesis as a means to achieve this. Maybe the company is facing challenges suitable for a thesis, or you identify in your thesis an urgent need to act in a new field, in which you will gain certain expertise interesting for the company. A different student may want to pursue an academic career. In this case, she may organize your thesis so that she can work closely with her supervisor on a hot and relevant research topic. She may get to know the researchers in the lab, realize whether she enjoys working as researcher, and, ideally, lay the foundation for her first publication. Other examples for decision opportunities include choosing the field of studies and the specialization, or studying abroad. Proactive, value-focused decision making does not only enhance the quality of life but also strengthens the empowerment of actively shaping one's life. Take advantage of this opportunity!

\section{Literature}

Bond, S. D., Carlson, K.A., Keeney, R. L., Generating Objectives: Can Decision Makers Articulate What They Want?, in: Management Science, Vol. 54 (2008), 56-70.

Keeney, R. L., Value-focused Thinking, A Path to Creative Decision Making, Cambridge 1992.

Keeney, R. L., Value-focused thinking: Identifying decision opportunities and creating alternatives, in: European Journal of Operational Research, Vol. 92(3)3 (1996), 537-549.

Keeney, R. L., Give Yourself a Nudge: Practical Procedures for Making Better Personal and Business Decisions, Cambridge 2020.

Siebert, J. U., Can Novices Create Alternatives of the Same Quality as Experts?, in: Decision Analysis, Vol. 13(4) (2016), 278-291. 
Siebert, J. U.; Hannes, C., The relative benefits of pursuing decision opportunities and decision problems (submitted. Siebert, J. U., Keeney, R. L., Creating More and Better Alternatives for Decisions Using Objectives, in: Operations Research, Vol. 63 (2015), 1144-1158.

Siebert, J. U., Kunz, R., Developing and Validating the Multidimensional Proactive Decision-Making Scale. In: Special Issue on "Behavioral Operations Research"der Zeitschrift European Journal of Operational Research, 249(3) 2016, 864-877. Siebert, J. U., Kunz, R., Rolf, P., Effects of proactive decision making on life satisfaction. European Journal of Operational Research, 280(1) 2020, 1171-1187.

Siebert, J. U., von Nitzsch. R., Das Jobauswahlproblem für Berufseinsteiger: Eine entscheidungstheoretische Anwendung - Teil 1: Problemstrukturierung in Ziele, Alternativen und Unsicherheiten, in: Wissenschaftliche Beiträge, Wirtschaftswissenschaftliches Studium, Vol. 47(10) (2018), 411. 